\title{
Post-irradiation Polymerization of Visible Light-activated Composite Resin
}

\author{
R.L. LEUNG, ${ }^{*}$ P.L. FAN, ${ }^{\dagger}$ and W.M. JOHNSTON
}

*Department of Restorative Dentistry, School of Dentistry, University of Southern California, Los Angeles, California 90089.0641, tCouncil on Dental Materials, Instruments and Equipment, American Dental Association, Chicago, Illinois 60611 , and $\ddagger$ Department of Dental Materials, School of Dentistry, The University of Michigan, Ann Arbor, Michigan 48109

The rate of post-exposure polymerization and the effects of initial polymerization on the final polymerization of visible lightactivated composite resin were studied. The extent of polymerization, as indicated by hardness values, was influenced by the exposure time to the photo-activating radiation and by the postexposure time. The timing of testing is critical when studying the properties of visible light-activated composite resins.

J Dent Res 62(3):363-365, March 1983

\section{Introduction}

The polymerization of a photo-activated composite restorative resin is influenced by the attenuation of the intensity of the photo-activating radiation during its passage through the translucent composite resin. Thus, the extent of polymerization decreases at increased depth of a restoration, as indicated by hardness measurements. The depth of cure and the curing pattern of ultraviolet (UV) light-activated composites have been reported by Salako and CruickshanksBoyd $^{1}$ and by de Lange et al. ${ }^{2}$ Factors affecting the depth of cure of UV light-activated composites were discussed by Cook. ${ }^{3}$ The dependency of polymerization of visible light-activated composites on light intensities and test methods was reported by Kilian.4,5 Comparisons of the depths of cure and transmission coefficients of UV lightactivated composites and visible light-activated composites were reported by Tirtha et al. ${ }^{6}$ Post-irradiation polymerization in photo-activated composite resins as a function of time, however, has not been reported. This study was to investigate the rate of post-exposure polymerization and the effects of initial polymerization on final polymerization of a visible light-activated composite resin.

\section{Materials and methods.}

A visible light-activated composite, Prisma-Fil GB, was used in this study. Cylindrical samples, $5 \mathrm{~mm}$ in diameter and $2.5 \mathrm{~mm}$ long, were prepared in brass molds, which were covered by Mylar and then exposed to a photoactivating light, Prisma-Lite, ${ }^{*}$ for ten, 15, 20, 40, 1 and $60 \mathrm{~s}$. Barcol hardness readings of the top surfaces and the bottom surfaces were taken by a hardness tester ${ }^{\circ}$ immediately after exposure and after ten, 20, 30, 40, 50, and 60 min, as well as after one and seven d.

Received for publication March 23, 1982

Accepted for publication September 23, 1982

This investigation was supported in part by Grant \#DE-0576102 from the National Institute of Dental Research, National Institutes of Health, Bethesda, MD 20205.

The au thors thank L.D. Caulk Co., Div. of Dentsply International, Inc., Milford, DE 19963, for materials and equipment used in this study.

$\S$ Lot Number 0227812, L.D. Caulk Co., Milford, DE 19963

**Serial Number 5399, L.D. Caulk Co., Milford, DE 19963 shade

I Manufacturer's recommended cure time for this thickness and

Barcol Hardness Tester GY2J 934-1, Barber-Colman Co., Rockford, IL 61101
The samples were stored at $37 \pm 2^{\circ} \mathrm{C}$ and $100 \%$ humidity in a light-proof container until hardness readings were taken. Two samples were prepared for measurement for each combination of exposure time and post-exposure storage time. Three readings were taken at each surface of these samples.

\section{Results.}

The average hardness values for the top and bottom surfaces for different exposure times and post-exposure times are shown in Table 1. The bottom surface at ten-second exposure time showed no measurable hardness at all post-exposure times and thus no detectable polymerization. The average hardness values, $H$, at the bottom surface at post-exposure time, $t$, are fitted to the equation as follows:

$$
H=H_{0}+H_{1}\left[1-\exp \left({ }^{t} / T_{1}\right)\right]+H_{2}\left[1-\exp \left({ }^{t} / T_{2}\right)\right]
$$

for each exposure time. The values of $\mathrm{H}_{0}, \mathrm{H}_{1}, \mathrm{H}_{2}, \mathrm{~T}_{1}$, and $\mathrm{T}_{2}$ obtained from curve fitting are shown in Table 2 . The curves are shown in Fig. 1. Statistical evaluations using analysis of variance showed that for each exposure and surface, except the abovementioned condition, there were differences among the hardness values for different post-exposure times. The results of multiple comparisons using the Student-Newman-Keuls test ${ }^{7}$ at $\alpha=0.05$ are shown in Table 1. A comparison of hardness values immediately after exposure and seven $d$ after exposure for the top and bottom surfaces is shown in Fig. 2 .

\section{Discussion.}

Hardness and other physical-mechanical properties of solid polymers are influenced by molecular weight. In

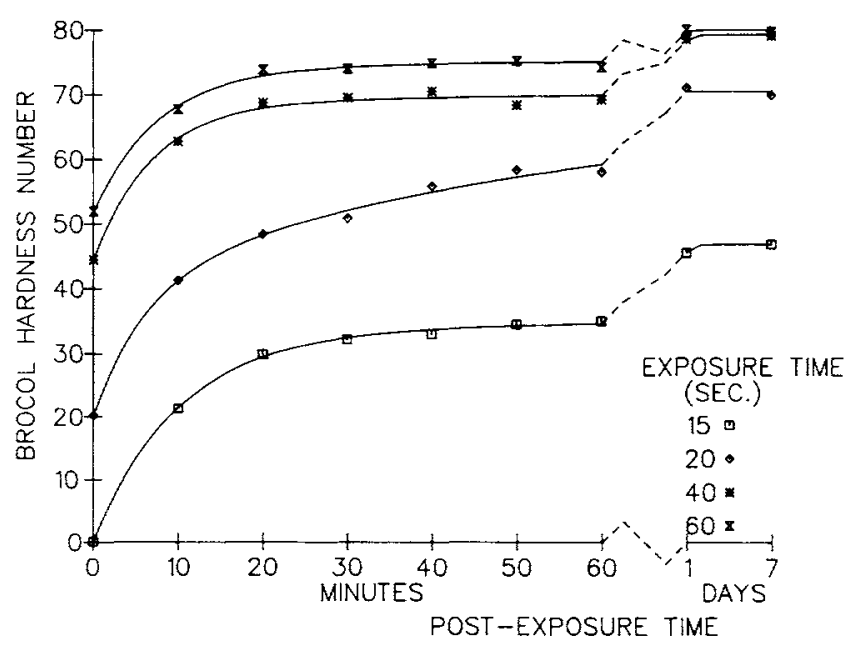

Fig. 1 - Curve fit plots of hardness values of the bottom surfaces vs. post-exposure time for different exposures. Experimental average hardness values are shown for comparison. 
TABLE 1

AVERAGE BARCOL HARDNESS NUMBER FOR TOP AND BOTTOM SURFACES FOR VARIOUS EXPOSURE TIMES AND POSTEXPOSURE TMES

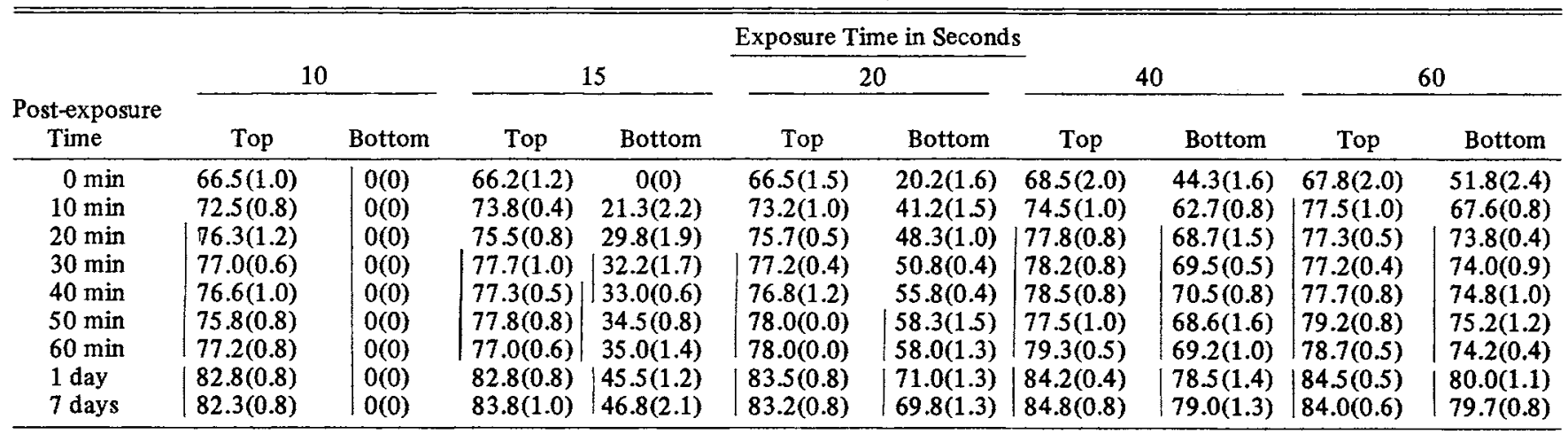

Numbers in parentheses indicate standard deviations.

Numbers connected by vertical lines are not significantly different at the 0.05 level.

general, higher hardness values are associated with higher molecular weights as a result of more extensive polymerization. ${ }^{8,9}$ The extent of polymerization of the visible lightactivated composite is associated with the Barcol hardness values. More extensive polymerization is indicated by higher hardness values. For the top surfaces of the sample at a specific post-exposure time, there was little difference in the degree of polymerization resulting from variations in exposure time to the photo-activating light.

For both the top surfaces and the bottom surfaces, the extent of polymerization increased with post-exposure time. The general trend for a specific exposure time and surface was a slow increase in hardness values for the first 20 min after exposure, followed by gentle leveling off up to $60 \mathrm{~min}$, and then slightly higher hardness values at one and seven $d$. In most cases, multiple comparison tests showed that there were no statistically significant differences for hardness values between 20 and $60 \mathrm{~min}$ of post-exposure, and between one and seven $d$. Thus, polymerization of the composite continued at a slow rate after exposure and essentially reached a termination point at approximately one $d$. The trend is reflected in the equation used to curve fit the experimental results.

At an exposure time of $20 \mathrm{~s}$, there is a more gradual continuous increase in hardness values with time, and this is reflected in the value of $T_{2}$. This may be because the system is slightly underexposed for photo-activation, thus influencing the rate of change in the degree of polymerization.

Post-irradiation increases in hardness of visible light composite resin between one $h$ and $24 \mathrm{~h}$ have been reported by Kilian ${ }^{10}$ and are consistent with the findings of this investigation.

However, results on UV light-activated resins were varied. $\mathrm{Cook}^{3}$ found no significant changes in hardness values for

TABLE 2

CURVE FITTING CONSTANTS AS SHOWN IN THE EQUATION FOR DIFFERENT EXPOSURE TIMES AND POST-EXPOSURE TIMES

\begin{tabular}{lccccc}
\hline $\begin{array}{c}\text { Exposure } \\
\text { Time }\end{array}$ & $\mathrm{H}_{0}$ & $\mathrm{H}_{1}$ & $\mathrm{~T}_{1}$ & $\mathrm{H}_{2}$ & $\mathrm{~T}_{2}$ \\
\hline 15 & 0 & 33.4 & 9.9 & 13.4 & 607 \\
20 & 20.1 & 20.5 & 6.1 & 29.7 & 61.5 \\
40 & 44.3 & 24.6 & 7.0 & 10.3 & 600 \\
60 & 51.8 & 22.6 & 7.8 & 5.6 & 447 \\
\hline
\end{tabular}

UV light-activated resins between one and $12 \mathrm{~d}$. Salako ${ }^{1}$ reported that there was no increase in hardness for UV light-activated resin measured immediately and up to three wk after irradiation. However, results by de Lange et al. ${ }^{2}$ indicated that there was some increase in hardness from one to three $d$. Such discrepancies may be due to differences in the composition of the materials and storage conditions, such as lighting, temperature, and humidity.

The above results suggest that the timing of testing is very critical when studying properties of composite resins.

The extent of polymerization at the bottom surfaces was highly influenced by the exposure time to the photo-activating light. An exposure of ten s produced no detectable polymerization even after seven $\mathrm{d}$. For each post-exposure time, an increase in exposure time was accompanied by higher hardness values, indicating higher degrees of polymerization. However, the differences for samples exposed to the photo-activating light for $40 \mathrm{~s}$ and $60 \mathrm{~s}$ were relatively less than the differences between 15 and 20 and $40 \mathrm{~s}$. This suggested that the effect of extended exposure above the manufacturer's recommended time was considerably less than the effect of underexposure.

Changes in hardness values, and thus the extent of polymerization, for the bottom surfaces with post-exposure time were also influenced by the exposure time to the

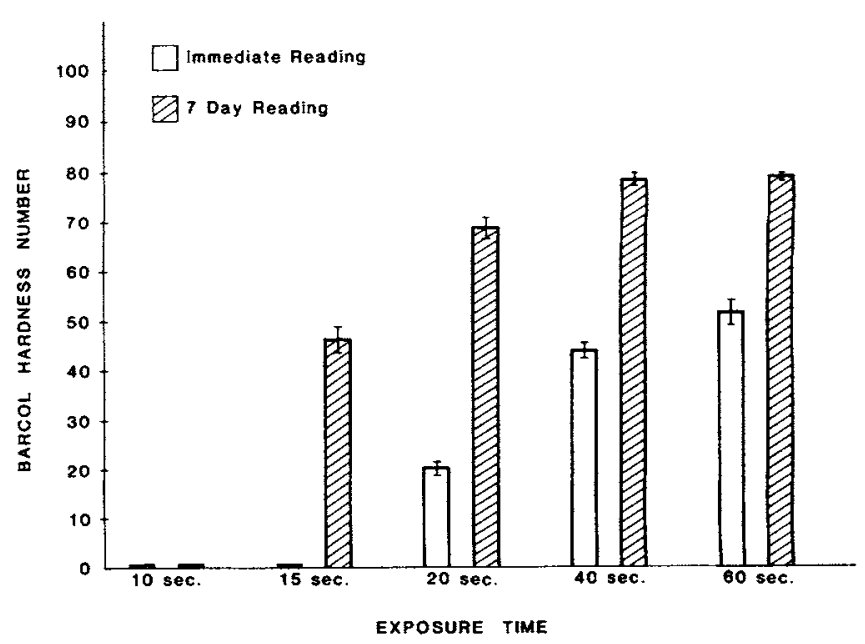

Fig. 2 - Relationship between hardness values immediately after exposure and seven $d$ after exposure for bottom surfaces. The bars represent standard deviations. 
photo-activating light. The magnitudes of change were larger for the bottom surfaces than for the top surfaces. This was especially evident for the post-exposure periods of up to $20 \mathrm{~min}$. Moderately underexposed samples (15- and 20 second exposure) showed higher increases (over 100\%) in hardness values in $20 \mathrm{~min}$. Samples exposed for the recommended time, $40 \mathrm{~s}$, and for extended time, $60 \mathrm{~s}$, showed relatively smaller increases (78\% and $54 \%$, respectively). Furthermore, the differences in hardness values for the bottom surfaces of samples exposed to the curing light for 40 and $60 \mathrm{~s}$ decreased with post-exposure time and converged toward each other after one $d$.

\section{Conclusions.}

The extent of polymerization of a photo-activated composite, as indicated by hardness values, was influenced by the exposure time to the photo-activating radiation and by the post-exposure time. The bottom surfaces of composite samples showed a more pronounced dependency in these factors. The extent of polymerization at the bottom surface increased with increased exposure time and post-exposure time. The increase was higher for moderately underexposed samples. When one studies the properties of a photo-activated composite, the timing of the testing is critical up to this termination point. Polymerization essentially reached a termination point after one d. Extended exposure to the photo-activating light did not significantly increase the final degree of polymerization.

\section{REFERENCES}

1. SALAKO, N.O. and CRUICKSHANKS-BOYD, D.W.: Curing Depths of Materials Polymerized by Ultraviolet Light, Br Dent J 146:375-379, 1979.

2. de LANGE, C.; BAUSCH, J.R.; and DAVIDSON, C.L.: The Curing Pattern of Photo-initiated Dental Composite, $J$ Oral Rehabil 7:369-377, 1980.

3. COOK, W.D.: Factors Affecting Depth of Cure of UV-Polymerized Composites, J Dent Res 59:800-808, 1980.

4. KILIAN, R.J.: Visible Light Cured Composites: Dependence of Cure on Light Intensity, IADR Progr \& Abst 58:No. 603, 1979.

5. KILIAN, R.J. and MÜLLER, T.J.: Light Cured Composites: Dependence of Test Results on Test Parameters, AADR Progr \& Abst 59:No. 203, 1980.

6. TIRTHA, R.; FAN, P.L.; DENNISON, J.B.; and POWERS, J.M.: In vitro Depth of Cure of Photo-activated Composites, $J$ Dent Res 61:1184-1187, 1982.

7. SOKAL, R.R. and ROHLF, F.J.; Biometry, San Francisco, CA: W.H. Freeman and Co., 1969, p. 239.

8. SPERATI, C.A.; FRANTA, W.A.; and STARKWEATHER, H.W.: The Molecular Structure of Polyethylene. The Effect of Chain Branching and Molecular Weight on Physical Properties, $J$ Am Chem Soc 75:6127-6133, 1953.

9. BILLMEYER, F.W., Jr.: Textbook of Polymer Science, New York: Interscience Publishers, 1962, pp. 221-226.

10. KILIAN, R.J.: The Application of Photochemistry to Dental Materials, Chemtech 11:678-680, 1980. 